Colleges \& Undergraduate Libraries, Vol. 8, No. 1, 2001, pp.31-40.

ISSN: (Print: 1069-1316) (Electronic: 1545-2530)

DOI: $10.1300 / J 106 v 08 n 01 \_04$

https://www.haworthpress.com/store/product.asp?sid=WAB4NV163GW79HFM1PA033JX0DGJ29QD\&sk

$\underline{\mathrm{u}=\mathrm{J} 106}$

http://www.informaworld.com/smpp/content $\sim \mathrm{db}=\mathrm{all} \sim$ content=a903586930 frm=abslink

(C) 2001 by The Haworth Press, Inc. All rights reserved

\title{
Evaluating the Use of Paraprofessionals at the Reference Desk
}

\author{
Nancy Courtney
}

\begin{abstract}
.
Medium-sized academic libraries have been experimenting with the use of paraprofessionals in reference services for over twenty years. The University of Dayton participated in the WisconsinOhio Reference Evaluation Program (WOREP) in 1988 and in 1997, one year after implementing a reference model using paraprofessionals. The factors influencing the development of a new model of reference, a description of the model, training procedures, and the evaluation results are described.
\end{abstract}

\section{BACKGROUND}

The use and effectiveness of paraprofessional staff at the reference desk has been discussed in the literature for many years. St. Clair and Aluri (1977) found that 80 percent of questions asked at the reference desk could be answered by trained nonprofessionals. A survey by Courtois and Goetsch (1984) reported that nonprofessionals were mainly used at reference desks at non-peak hours and to cover for librarians who are unavailable. A study by Murfin and Bunge (1988) of data from 20 libraries found that librarians scored significantly higher than paraprofessionals in a measure of patron satisfaction. Beth S. Woodard (1989) reported on the effectiveness of staffing an academic library information desk with graduate students and nonprofessionals and found that 70.7 percent of the transactions were handled correctly. A national survey (Oberg 1992) found that 88\% percent of the Association of Research Libraries and 66 percent of a sample of Carnegie Classification libraries used paraprofessionals to work at reference or information desks, with larger libraries more likely to use them than smaller libraries. Brandeis University (Massey-Burzio 1992) introduced a model using an information desk staffed by graduate students and a research consultation office, where librarians meet with clients. Stalker and Murfin (1996) reported on the high quality of reference service Brandeis achieved using this model as measured by their scores on the Wisconsin-Ohio Reference Evaluation Program.

In general, reference departments use nonprofessionals to provide service for many hours with few staff and to avoid burnout among the professional librarians, who are often fulfilling multiple roles within the library.

\section{A MODEL AT THE UNIVERSITY OF DAYTON}

In 1996, the University of Dayton Roesch Library implemented a model of reference service that uses full-time paraprofessional staff at the reference desk and has significantly 
decreased the number of hours that reference librarians are scheduled at the desk. With some modifications, the model is still in use and is considered a successful use of resources in a busy reference environment.

The University of Dayton is a comprehensive, Catholic university offering a broad range of undergraduate programs as well as master's and doctoral programs in selected areas. Roesch

Library is the primary campus library, employing 13 faculty librarians and 30 FTE support staff, and serving a university population of approximately 6,000 undergraduates, 4,000 graduate students, and 400 full-time faculty. The reference desk is staffed 73 hours per week. Before the new model was implemented, 4 full-time reference librarians staffed the desk with assistance from librarians in other departments. Each full-time reference librarian worked from 12 to 15 hours per week at the reference desk and shared weekend rotation. Occasionally, a part-time professional librarian was hired to assist with evening and weekend hours and to supplement staffing during summer vacations. The desk was double-staffed only during the evening hours Monday through Wednesday.

Under the new model, the reference desk is still staffed 73 hours per week. Two full-time paraprofessional reference assistants, with help from a third paraprofessional who works primarily in government documents, provide staffing 59 hours per week. Librarians staff the desk 23 hours per week, including 9 hours paired with a reference assistant, with an additional 20 hours per week when a librarian is scheduled as backup for the reference assistant.

\section{FACTORS INFLUENCING THE DEVELOPMENT OF A NEW MODEL}

The implementation of the new reference service model coincided with a broader reorganization of the entire library. The traditional hierarchical structure consisting of library director, assistant directors for public and technical services, and an array of department heads was abandoned in favor of a flattened structure in which functional teams report to one of three positions: Head of Client Services, Head of Bibliographic Management, and the Coordinator and Head of Collection Management. All librarians participate in the management of the library through membership on the Services and Resources Council and in collection development. The rest of their duties are outlined in individual portfolios. The reference team is comprised of the five librarians who are primarily involved in reference, including the Head of Client Services, and the reference assistants

The broadening of the scope of reference librarians' duties to include management and collection development functions was one of several motivating factors in the decision to use paraprofessionals at the reference desk. Reducing the number of hours librarians spent at the desk allowed them to spend time on collection development, on more complicated reference interactions, and on a growing bibliographic instruction program that had also strained librarians' time. Another factor was the changing nature of reference work itself. The explosion in the number of electronic information resources used directly by patrons in the reference room meant that more of the librarians' time at the desk was spent in repetitious tasks such as fixing jammed printers, loading paper, rebooting machines, and showing patrons how to mark and print citations.

The physical layout and location of the reference room dictated certain aspects of the model. The reference desk is not visible from the lobby where patrons enter the building. The main lobby of the library contains the circulation desk, elevators, and an art gallery/lounge. There are no public computers in this area since it proved too difficult to wire. The library 
discarded an initial plan that called for an information desk in the lobby staffed by paraprofessionals. The staff would not be able to assist patrons on the computers in the reference room, which is accessed through one doorway at the back of the lobby.

In the reference room, the librarians' offices are arranged in an L-shape around the reference desk area. The reference desk phone is audible from the offices and can be picked up from the librarians' telephones. This layout allowed the reference desk to become a de facto information desk, while the librarians could use their own offices as reference consultation space.

\section{HIRING AND TRAINING PARAPROFESSIONALS}

Since there were not immediate funds to hire two full-time staff positions, a preliminary version of the model was put into place in January 1995 by hiring two part-time paraprofessionals to work two evenings per week each and alternate Sundays. When additional funds became available in early 1996, their hours were expanded to full-time and the model was fully implemented.

Applicants were required to have a college degree or two years of library experience and some college. Training or tutoring experience was preferred as was any sort of experience in the use of computer information resources. Once hired, the new reference assistants attended training sessions over a three-week period. All reference librarians participated in the training schedule that included observation at the reference desk ("shadowing" the reference librarian), discussion of policies and procedures, readings about service philosophy and the reference interview, orientation to the library building, an in-depth walkthrough of the reference collection, and intensive training on reference databases. It was important to involve each librarian in the training process in order to give the assistants an exposure to different styles of reference work and the variety of strengths among the librarians and to allow the librarians and assistants to become comfortable with one another. Each assistant was given a training notebook containing maps, brochures, lists of periodical indexes by title and subject, a descriptive list of computer databases and any "help" guides available, an outline of Library of Congress classification, and a referral sheet listing examples of questions that needed to be referred to specific people or other areas of the library, such as requests for bibliographic instruction classes or faculty carrels. All items in the notebooks were referred to or used in the training sessions and the notebooks continued to be used as a reference by the assistants who added their own information and "cheat sheets" as they grew into the job.

Database training consisted of two four-hour sessions in the library's training lab with hands-on practice. The training focused first on understanding generic concepts of database searching (fields, elements of a record, Boolean operators, etc.) and becoming familiar with the specific interfaces involved rather than the individual databases. For example, ERIC, Disclosure, and Compendex were all considered at the same time, even though the contents are very different, because they used the same interface. Special attention was given to frequently used databases. Typical searches were used as examples in the training.

\section{REFERENCE ASSISTANT DUTIES}

As the providers of front-line reference service, the reference assistants are expected to handle directional questions and questions that can be answered using the ready reference or 
"desk" collection as well as the online catalog. They assist patrons in choosing and using electronic or printed indexes, with accessing databases and printing, downloading, and emailing records, and they maintain the reference computers by supplying paper and clearing jams. A reference librarian is specifically scheduled as a backup from 2:00 until 5:00 p.m. Monday through Thursday but the assistants are encouraged to refer questions they cannot answer to any reference librarian who is available. If there is no one waiting at the reference desk, the assistant often follows the librarian and patron through the process of answering the referred question in order to gain new knowledge of sources. On Sundays and Thursday evenings an assistant staffs the desk alone. In the beginning, assistants were encouraged to take written requests from patrons who needed to be referred and a librarian would contact them. However, this plan was soon abandoned in favor of simply referring the patron to a librarian during appropriate hours.

Since the reference assistants work overlapping hours on weekday afternoon, there is an opportunity for a break from work at the reference desk. Each assistant is assigned off-desk duties such as filing looseleaf services, printed indexes, and pamphlets, retrieving documents and articles for off-campus students, maintaining the library bulletin boards, sorting approval slips, and other special projects. Assistants also regularly shelve the reference desk collection, the career and business reference tables, and maintain the appearance of the computer workstations.

\section{WOREP}

The Wisconsin-Ohio Reference Evaluation Program (WOREP) is an evaluation tool that measures reference success by matching evaluation responses to reference transactions from both the librarian and patron (Bunge and Murfin 1987). The WOREP uses a set number of forms, usually 100 to 200. A survey form is given to each patron who asks a reference question during the sample period until all the forms are gone. Directional questions are handled by a separate form and are not part of the score. Patrons are asked whether they found what they wanted completely, partially, or not at all, whether or not the librarian understood what they wanted, was considerate, spent enough time with them, provided clear explanations, was busy, etc. The librarian's form is more detailed and asks about the type of question (short answer, particular text or author needed, explanation of catalog or reference sources), conditions involved in answering the question (e.g., patron in a hurry, hard to understand, collection weak in that area, how busy it is at the desk), as well as the subject area and type of materials used to answer the question. The participating library receives a report of its own scores on each item as well as the corresponding score of all libraries in the database and those in the same size category. Medium-sized libraries are those with 500,000 to 999,999 volumes.

\section{RESULTS}

In February 1997, after the complete model had been in place for one year, the reference team participated for the second time in the WOREP. The paraprofessional model was not a specific factor in the decision to participate, but the results are of interest nonetheless. The Roesch Library reference department had participated in the program once before in 1988, when the reference desk was staffed only by librarians (in fact, there was only one personnel change among the librarians between the two evaluations) and when computer information resources were still comparatively limited. The WOREP considers the reference success rate to be the percentage of times the patron reports having found exactly what was wanted and being fully 
satisfied. A success rate of $60 \%$ or more is considered good or excellent. In Murfin and Bunge's study (1988) of WOREP data, paraprofessionals achieved a success rate of 50.5 percent overall compared with 60.4 percent for professionals. In 1988, Roesch Library's success rate, using only professionals, was 60 percent. In 1997, using both paraprofessionals and professionals, the success rate was 62.50 percent overall with the professionals' success rate 65.38 percent compared with the paraprofessionals' rate of 62.26. The paraprofessionals had handled 63.1 percent of the total reference transactions during the survey. The overall success rate of 62.5 percent is compared with the average score of 57.88 of all the WOREP participating libraries and the average score of 60.56 for WOREP libraries of a similar size as reported in the statistical results given to the library by WOREP at the end of the survey.

\section{DISCUSSION}

Informally, the reference librarians and assistants perceive the model to be a success. Not only do the assistants frequently refer questions, they like to stay involved with a question, and check back later with the librarian for the answer. This enhances assistants' training. The model has freed librarians to do collection development work and bibliographic instruction classes, and several projects such as designing the library's Web interface, implementing e-reserves, and creating an online tutorial. Training is ongoing in monthly reference meetings of both librarians and paraprofessionals. New databases are introduced and time is spent discussing reference sources, difficult questions, and clarifying policies. One of the few concerns expressed by the librarians is that it is harder for them to maintain reference skills with fewer hours on the reference desk. However, it is not clear that time on the desk is the main cause. The proliferation of new databases and Internet resources has meant that librarians are using more sources than ever before and are less familiar with the sources they use.

The model has not only allowed the reference librarians to broaden their responsibilities and fulfill a greater role in the management of the library, but also offered a professional development opportunity for staff. The position of reference assistant is ranked at the highest level of the library's clerical and technical staff hierarchy.

\section{CONCLUSION}

Medium-sized libraries are often caught in the middle between the focused nature of the small liberal arts college and the complexity and greater resources of the large research library. With limited staff, collections, and budgets, they try to serve both the needs of undergraduate and graduate programs as well as the research needs of faculty who were trained at much larger institutions. Paraprofessionals have often been used effectively in the technical services areas of these libraries. As this experience demonstrates, they can also be used to great advantage in the reference room without sacrificing quality service.

In their examination of the Brandeis model, Stalker and Murfin (1996) report that medium-sized libraries in general score better on the WOREP than large or small libraries. They propose several possible factors that may account for this: centralized reference collections that are neither too small to be adequate nor too large to be housed in one location, a reliance (at that time) on print resources that are more easily consulted in one place, and institutional populations that do not overwhelm the ability of the library to provide staff to serve them. Brandeis scored a $72 \%$ success rate on the WOREP. Graduate students, not paraprofessionals, answer low-level 
questions and refer reference questions to the reference librarians. Their score represents primarily the success of the reference librarians as there were not significant numbers of student transactions to evaluate. Stalker and Murfin credit the time spent on each reference question as the major factor in the library's success. Brandeis librarians spend more time on questions than is the norm for medium-sized libraries and their tiered model allows them to spend the extra time with the patron. In the University of Dayton experience, paraprofessional staff accounted for well over half the reference transactions during the WOREP evaluation and both paraprofessionals and professionals scored above 60 percent. Further study is needed to determine the factors for paraprofessional success but ongoing training, the fact that they are full-time permanent staff with the opportunity to accumulate knowledge and experience, and a certain consistency in the kinds of reference questions that are asked seem to be likely determinants.

The WOREP is an excellent tool for benchmarking reference success both against other libraries and a library's own past performance. It also has the advantage of separating out distinct factors for consideration such as a communication difficulty with patrons or collection weakness in certain areas and it allows a library to distinguish between paraprofessional and professional performance. Regular participation in the evaluation, perhaps once every two or three years, would provide a useful picture of reference service over time. For the evaluation to be effective, every member of the reference department must be committed to the process in order to ensure that forms are filled out thoroughly and that patrons are encouraged to provide responses.

The use of paraprofessionals at the reference desk can enhance service in medium-sized libraries by freeing reference librarians to spend more time with patrons, to improve the libraries' collections, and to provide library instruction. Proper training and regular evaluation ensure that the quality of service at the reference desk is maintained.

\section{REFERENCES}

Bunge, Charles A., and Marjorie E. Murfin. "Reference Questions-Data from the Field." $R Q 27$ (Fall 1987): 15-18.

Courtois, Martin P., and Lori A. Goetsch. "Use of Nonprofessionals at Reference Desks."

College \& Research Libraries 45 (Sept. 1984): 385-391.

Massey-Burzio, Virginia. "Reference Encounters of a Different Kind: A Symposium." Journal of Academic Librarianship 18 (Nov. 1992): 276-286.

Murfin, Marjorie E., and Charles A. Bunge. "Paraprofessionals at the Reference Desk." Journal of Academic Librarianship 14 (Mar. 1988): 10-14.

Oberg, Larry R., Mark E. Mentges, P.N. McDermott, and Vitoon Harusadangkul. "The Role, Status, and Working Conditions of Paraprofessionals: A National Survey of Academic Libraries.” College \& Research Libraries 53 (May 1992): 215-238.

St. Clair, Jeffrey W., and Rao Aluri. "Staffing the Reference Desk: Professionals or Nonprofessionals?” Journal of Academic Librarianship 3 (July 1977): 149-153.

Stalker, John C., and Marjorie E. Murfin. "Quality Reference Service: A Preliminary Case Study.” Journal of Academic Librarianship 22 (November 1996): 423-429.

Woodard, Beth S. "The Effectiveness of an Information Desk Staffed by Graduate Students and Nonprofessionals.” College \& Research Libraries 50 (July 1989): 455-467. 